\title{
7
}

\section{State-of-the-Art Analysis of the Usage and Potential of Automation in Logistics}

\author{
Helmut Zsifkovits, Manuel Woschank, \\ Sakgasem Ramingwong and Warisa Wisittipanich
}

\subsection{Introduction-Automation in Production Logistics}

In general, logistics management can be seen as one of the major success factors increasing the competitive advantage of small- and medium-sized enterprises (SME) and industrial enterprises. During recent years, logistics-related technologies have fundamentally changed. They have become more affordable and therefore within reach of SMEs. These technologies assist them in improving their efficiency by

H. Zsifkovits $(\bowtie) \cdot$ M. Woschank

Chair of Industrial Logistics, Montanuniversitaet Leoben, Leoben, Austria e-mail: helmut.zsifkovits@unileoben.ac.at

M. Woschank

e-mail: manuel.woschank@unileoben.ac.at

S. Ramingwong

Department of Industrial Engineering, Chiang Mai University, Chiang

Mai, Thailand e-mail: sakgasem.ramingwong@cmu.ac.th

(C) The Author(s) 2020 
using transport management systems (TMS), warehouse management systems (WMS), enterprise resource planning systems (ERP), product lifecycle management solutions, inventory management software, etc. (Inboundlogistics 2018). In this context, a multitude of empirical studies were able to demonstrate significant positive effects of improvement initiatives in logistics on various performance measures (e.g., costs, delivery times, quality, and/or flexibility).

Significant positive effects were investigated by Agus and Hajinoor (2012) on product quality performance and business performance, by Birou et al. (2011) on financial performance, by Chen et al. (2007) on firm performance, by Danese and Kalchschmidt (2011) on operational performance, by Juga et al. (2010) on service quality and loyalty, and by Spillan et al. (2013) on firm competitiveness.

Thereby, logistics management research and practical applications have isolated a multitude of success factors, which can be used to design and improve a logistics system. Besides basic principles, e.g., organizational measures, improved planning heuristics, flow orientation, process alignment, and product design, automation can be identified as one of the major opportunities for logistics to improve overall performance and competitiveness.

In this context, automation and robotics in logistics systems was ranked as one of the most important megatrends for logistics, among others, e.g., data analytics and artificial intelligence, autonomous trucks, unmanned aerial vehicles, cloud computing, and blockchain technology (SCI Verkehr 2018). Moreover, Tractica (2012) has forecast that the potential sales of service robots in logistics will rise to US\$31,910 billion in 2020. This will also increase the necessity for a redesign of jobs in production and logistics (LivePerson 2018) and a realignment of the professional working environment.

W. Wisittipanich

Center of Excellence in Logistics and Supply Chain Management, Chiang Mai University, Chiang Mai, Thailand e-mail:warisa.w@cmu.ac.th 
In conclusion, automation in logistics holds considerable potential and great opportunities for performance-enhancing incentives. According to Groover (2008), the reasons for implementing automated processes can be summarized as follows:

- Increased labor productivity

- Lower labor costs

- Mitigation of the effects of labor shortage

- Reduction and/or elimination of routine manual and clerical tasks

- Improved workplace safety

- Improved product quality

- Reduced lead time

- The accomplishment of processes that cannot be done manually, and

- The avoidance of high costs in comparison to manual processes.

Thereby, the automation of material flow processes in logistics systems depends on the integration of information and communication technologies, the compatibility of hardware and software, standardized interfaces, modular designed systems, consistent storage of information, and interoperable hardware and software (Krämer 2002). Moreover, modern automation is highly dependent on state-of-the-art identification technologies and technological concepts, which will be briefly outlined in the next section.

\subsection{Problem Formulation and Methods/ Methodology}

The importance of automation approaches in logistics systems is mostly recognized by larger companies, mainly in the industrial environment. Unfortunately, small- and medium-sized companies still lack knowledge regarding the effects, state-of-the-art technologies, and the implementation of automation concepts.

Therefore, this chapter systematically discusses studies that investigate the effects of automation in logistics systems on various performance 
measures. The authors present a structured analysis of enablers of automation in logistics systems by focusing on both, identification technologies and technological concepts for automation. Moreover, the authors present recent developments in automation (e.g., agent-based automation through enhanced process control, automated guided vehicles and robots in logistics systems, conveyor belts and sorting systems, automation through augmented reality $[\mathrm{AR}]$ ) and introduce a case study of automation by using conveyor belts and sorting systems in an SME in Thailand.

\subsection{Enablers of Automation in Logistics}

The successful implementation of automation in logistics is dependent on a variety of organizational, procedural, technological, and socio-economic success factors. In this context, recent literature has developed a multitude of partial and divergent frameworks, models, and conceptualizations which should be used to support the efficient implementation, continuous operation, and further development of digitalization strategies of Industry 4.0 initiatives. However, existing conceptualizations can still be regarded as unspecific, because of a missing holistic approach and/or a missing unambiguous classification (Zsifkovits and Woschank 2019).

In this context, the authors will further discuss identification technologies and technological concepts for automation as one of the main prerequisites for enhanced material and information flow processes in logistics.

\subsubsection{Identification Technologies for Automation}

The successful implementation of automated logistics processes depends on the consistent identification, tracking and tracing of raw materials, semi-finished components, and finalized goods.

One prerequisite of automation is that the products in logistics systems constantly contain all necessary information. Therefore, 
state-of-the-art identification technologies should be used to ensure clear identification and constant tracking within the entire supply, production, and distribution process.

Moreover, modern enterprises try to implement smarter products which are based on product-enabled information devices (PEID), such as RFID, sensors, actors which allow the interoperability of systems by dynamically exchanging product data and additional in-depth information regarding the lifecycle management (Kiritsis 2011) and further process-relevant, real-time information.

Another often-recognized trend is the shifting from identification on batch level to identification on product level. This is forced by market requirements (e.g., product liability laws), efficiency initiatives (e.g., lower number of recalls in case of possible product errors), and enhanced planning strategies (e.g., lower quality management incentives based on a better understanding and control of the production process).

Furthermore, environmental conditions in production facilities (e.g., changes in temperature, heat, dust, changes due to surface treatments) lead to enhanced requirements for new identification technologies. In most cases, the identification on product level will require a combination of different identification technologies because the surface condition of the products will constantly change during the production process.

In the next section, the authors outline the most important identification technologies as enabling factors for automation in logistics. Direct labeling technology identifies the material directly without any additional tools. Indirect labeling uses additional code carriers, e.g., various labeling technologies or RFID tags (ten Hompel et al. 2008).

Direct labeling can be realized by using lasers (McKee 2004), lasers on painted ground layers (InfoSight Corporation 2017), direct printing with inkjet technology (ten Hompel and Schmidt 2005), marking by needle printing (Seegert 2011), and labeling by stamping devices (Henning and Müller 2001).

Indirect labeling is established by using thermal-printed labels (Drews 2008; ten Hompel et al. 2008), sheet metal labels (Henning and Müller 2001), and/or radio-frequency identification (RFID) devices (Finkenzeller 2015). 
It is important to note that research into automation tries to further develop both direct and indirect labeling technologies, in order to ensure better identification, particularly in harsh industrial environments. For example, printed labels nowadays are able to resist temperatures up to $1100{ }^{\circ} \mathrm{C}$ (Alpine Metal Tech GmbH 2019) and RFID tags can now be used on metallic materials without interferences (Feinbier et al. 2011).

An RFID tag for metals can be used without interference of the RFID signal. Furthermore, research is constantly developing new technologies for the identification and the continuous tracking and tracing of bulk material (Weichbold and Schuster 2017). For further elaboration of identification and traceability, we refer to Sect. 7.3.

\subsubsection{Technological Concepts for Automation}

Moreover, automation depends on the implementation of new technological concepts. In this section, the most advanced concepts of CPS, IoT, and PI will be briefly outlined and their potential application in automation will be discussed (Zsifkovits and Woschank 2019).

Cyber-Physical Systems (CPS) are physical objects or structures, such as products, devices, buildings, means of transport, production facilities, and/or logistics components, that include embedded systems in order to ensure interactive communication (Bauernhansl et al. 2014). The systems are connected through local and global digital networks (Broy 2010) by using sensors and actors in closed control loops (Lee 2010). CPS detect, analyze, and capture their surrounding environment by using sensors combined with available information and services. Moreover, actors are used to interact with physical objects. CPS act autonomously, in a decentralized way, can easily build up networks among themselves, and can independently optimize themselves according to the principles of self-similar fractal production systems. The Smart Factory interacts with human resources and/or machines and is able to organize itself in a decentralized, real-time way (Bauernhansl et al. 2014). A virtual image of the real production environment is permanently analyzed and updated with real-time information. Therefore, 
the virtual environment, often entitled the "digital twin" is always synchronized with information from the real environment. This can be seen as the starting point in order to connect the Internet of Mankind to the IoT and to the Internet of Services (IoS) (Padovano et al. 2018).

Internet of Things (IoT) can be seen as an essential and important part of the CPS which is often associated with RFID technologies. Thereby, the IoT is used to identify and track objects (e.g., products, container, machines, vehicles) in logistics systems and supply chains. The objects are constantly processing information from their surrounding environment and can be unambiguously allocated, which increases the effectiveness and efficiency of all related monitoring and control processes (Boyes et al. 2018; Borgmeier 2017).

Physical Internet (PI) is an open, standardized, worldwide freight transport system based on physical, digital, and operative interconnectivity by using protocols, interfaces, and modularization. A provider-free, industry-neutral, and border-free standardization is one of the basic requirements for the usage of the PI which connects and virtualizes material flows, in analogy to the concept of the digital internet. Moreover, standardized containers and carriers are used to ensure maximum utilization of transport vehicles and a better usage of spare capacities. These principles can be applied to internal logistics systems, as well as transportation networks by using self-controlling, autonomous systems in transport and storage processes as one of the central elements of the PI. The usage of shared transport capacities, storage locations, hubs, and delivery points will have a positive effect on both economic (e.g., short transportation times, lower costs of human resources) and ecological (e.g., reduction of traffic and emissions) effects (Montreuil 2011; Pan et al. 2017).

\subsection{Discussion of Automation Approaches}

In general, there is a multitude of opportunities for implementing automation concepts in logistics systems in order to improve the overall efficiency. In this context, based on a systematic literature review, Granlund 
(2014) has clustered and summarized the most commonly occurring applications and types of mechanized automation as follows:

- Automated loading and unloading systems

- Automated guided vehicles (AGVs)

- Automated storage and retrieval systems (AS/RS)

- Automatic fork-lift trucks for mechanized handling

- Various types of carousels, conveyor belts, and conveyor-based sorting systems

- Industrial robots/robotics

- Item-picking devices

- Lift and turntables/aids

- Linear actuators

- Mechanized palletizing

- Moving decks and screening and/or sorting systems.

In the next section, we will discuss the most promising developments for automation, namely, agent-based automation through enhanced process control, automated guided vehicles and robots in logistics systems, conveyor belts and sorting systems, automation through AR, and automation through modularization strategies in SME.

\subsubsection{Agent-Based Automation Through Enhanced Process Control}

In logistics systems, agent-based automation strategies can be used for the self-organization of the material flow process. Thereby, agents communicate autonomously by constantly transferring information about targets, system conditions, and occurring restrictions (Gudehus 2012). For example, agent-based-controlled AGVs resulted in $25.5 \%$ lower processing times, $7.9 \%$ reduced traveled distances, and $2.42 \%$ lower empty runs, which leads to a more robust and more flexible logistics system (Ullman and Sauer 2013). 


\subsubsection{Automated Guided Vehicles (AGVs) and Robots in Logistics Systems}

In general, AGVs are becoming more and more important for industrial companies and for SME. Thereby, Mehami et al. (2018) have identified the ability of reconfiguration, flexibility, and customizability, as the main success factors for effective AGV implementation. In addition, warehousing processes are optimized by the usage of autonomous robots, intelligent carriers, and advanced assistance systems for manmachine interaction (Glock and Grosse 2017).

\subsubsection{Conveyor Belts and Sorting Systems}

Nowadays, conveyor systems are quite easy to implement. The selection of the conveyor system is dependent on the product that needs to be moved, on the available space, and the space needed for further operations. Conveyors can be located on the ground and/or positioned overhead and can be integrated by using sensors and actors.

Thereby, the machines, devices, systems, and products have the capability to connect with each other without any human intervention (McGuire 2009; Jeschke et al. 2017). Conveyor systems are not as flexible as AGVs, but with frequent transport tasks, the conveyor system is a good solution for automation due to their mechanical simplicity, reliability, and ability to transfer materials very efficiently and flexibility (Greenwood 1988).

\subsubsection{Automation Through Augmented Reality (AR)}

In the automation of logistics processes, $\mathrm{AR}$ is used to enable man-machine interactions through the integration of real and virtual information by using cameras, smartphones, tablets, AR helmets, and data glasses (Jost et al. 2017).

$\mathrm{AR}$ is often used to support picking operations. In this context, the pick-by-vision technology can lead to an enhanced picking efficiency 


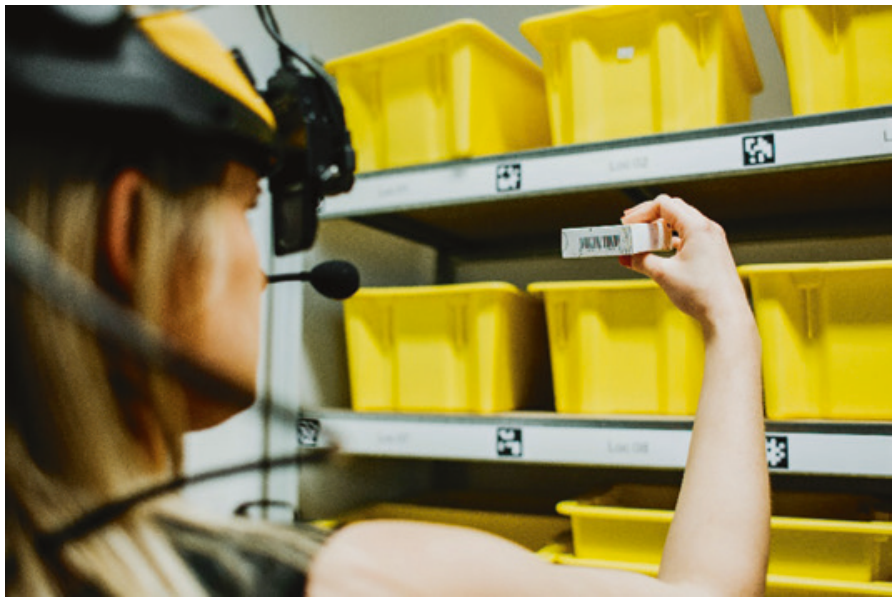

Fig. 7.1 Picking processes by using augmented reality devices (Reproduced with permission from University of Leoben, Chair of Industrial Logistics)

(of up to 25\%) by simultaneously eliminating almost all picking errors (Deutsche Post AG 2015). This approach was also transferred to packaging operations leading to higher usage of packaging space (up to $19 \%$ more) and lower costs (-30\%) (Mättig et al. 2016).

Figure 7.1 displays pilot implementation of a picking process using an AR device (AR helmet) which could also be transferred to the environment of SME.

\subsubsection{Automation Through Modularization Strategies}

The automation of packaging processes will gain enormously in importance. In this context, researchers are developing modular load carrier strategies to support automation in logistics systems.

In this context, packaging processes are becoming more and more important. Various researchers are developing modular load carrier strategies in order to support automation in logistics systems. Thereby inefficiencies in transport, quality control, administration, and maintenance should be avoided and sustainability should be increased through new pooling and sharing concepts (Zsifkovits and Woschank 2019). 


\subsection{A Case-Conveyor Belts and Sorting Systems Case Study: Medium-Sized Logistics Service Provider in Thailand}

The case study company is a local logistics service provider (LSP) in Northern Thailand. The company provides port-to-door services for customers in Northern Thailand and in the Bangkok metropolitan area. The company uses semi-trailer trucks to deliver goods from their drop-point distribution center (DC) to the destination DC. Then the goods are cross-docked and delivered to the consignees' door by small trucks. Thereby, the range of goods includes construction materials, textile and garment, paper, automotive parts, food and snacks, vegetables, and flowers. Most of the customer's requirements are lesser than a full truckload.

The size, weight, and dimension of goods can vary in a wide range. The packaging also comes in different sizes due to the nature of the products. For examples, snacks come in light boxes. Fabric rolls are often heavy and long. Tyres are individually wrapped up in plastics or packing paper (Fig. 7.2).

The investigated logistics operation is cross-docking where the goods must be unloaded from trucks to the cross-dock area in DC. Today, DC operators manually pick up the goods by hand from the delivery truck and put them on the vertical conveyor belt. Then the goods will

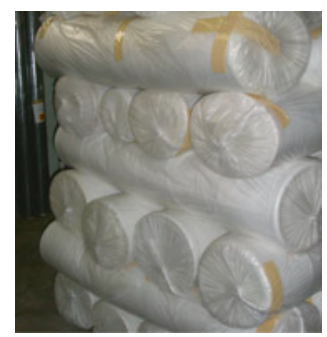

(a) Heavy and Long Fabric Rolls

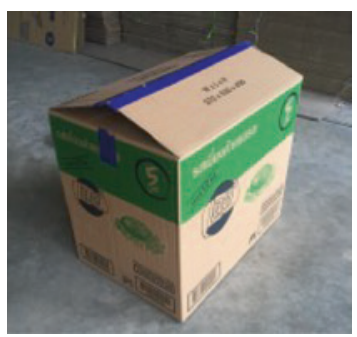

(b) Light Snack Box

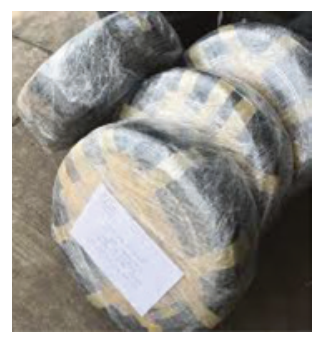

(c) Packed Second handed Tyres

Fig. 7.2 Example of delivered goods (DG) (Reproduced with permission from University of Chiang Mai, Department of Industrial Engineering) 


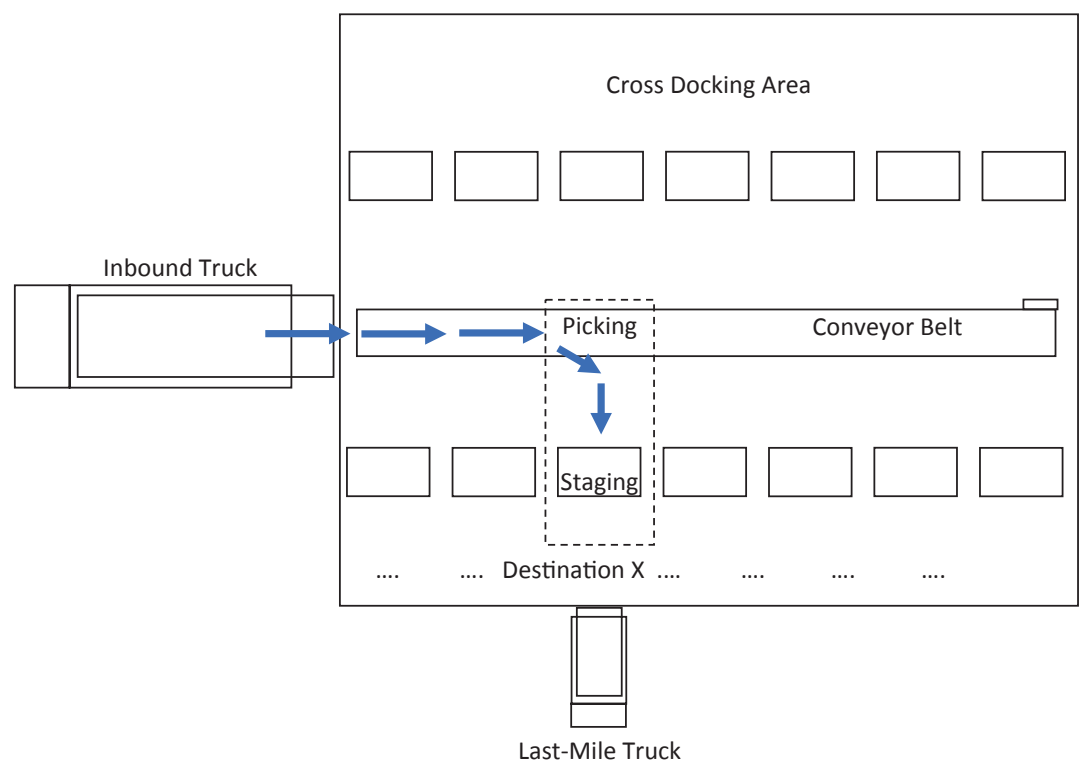

Fig. 7.3 Cross-docking operation

be sorted aligned to their designated destination. The conveyor belts are straight and approximately 20 meters long. There are 14 destinations of last-mile delivery aligned along the belt (Fig. 7.3).

If the good, which belongs to destination $\mathrm{X}$, arrives at the picking area of destination $\mathrm{X}$, the last-mile operator of destination $\mathrm{X}$ will pick up the good from the belt and transfer to destination $X$ staging area, where the last-mile delivery will be arranged.

At this picking area, with 14 possible destinations, the goods are identified by the packing label where the picker must recognize the address and determine if it belongs to his/her destination. The identification is manual and requires experiences of picker in order to accurately pick the right goods according to their designated destination.

Today, at this case study DC only, there are more than 30 trucks hauling from 6 Bangkok DCs with more than 10,000 pieces of goods per normal working day. At present, Barcode is embedded with the parcel label. However, it is used only to cross-check the goods with the database once staged. It is not used for AutoID sorting. 
The process requires one picker per destination and 2 more DC operators to stage and manage the last-mile delivery per destination. Therefore, at the conveyor belt, there are 42 workers, excluding the DC manager and 3 more unloading workers at the truck. The process is labor-intensive and hence expensive.

The company is now suffering with the labor cost and productivity. Moreover, operator turnover is high due to the hard work and working condition. Staffing becomes more difficult. Thus, the concept of Industry 4.0 of using conveyor belts and sorting systems is considered.

According to expert consultancy under Industry 4.0 scheme, the company was suggested the following potential improvements:

(a) To use inclining conveyor belt to assist truck unloading. This will increase the speed of unloading and reduce the labor cost in loading. The initial investigation suggests that the Payback Period is less than 6 months on the equipment investment (Fig. 7.4).

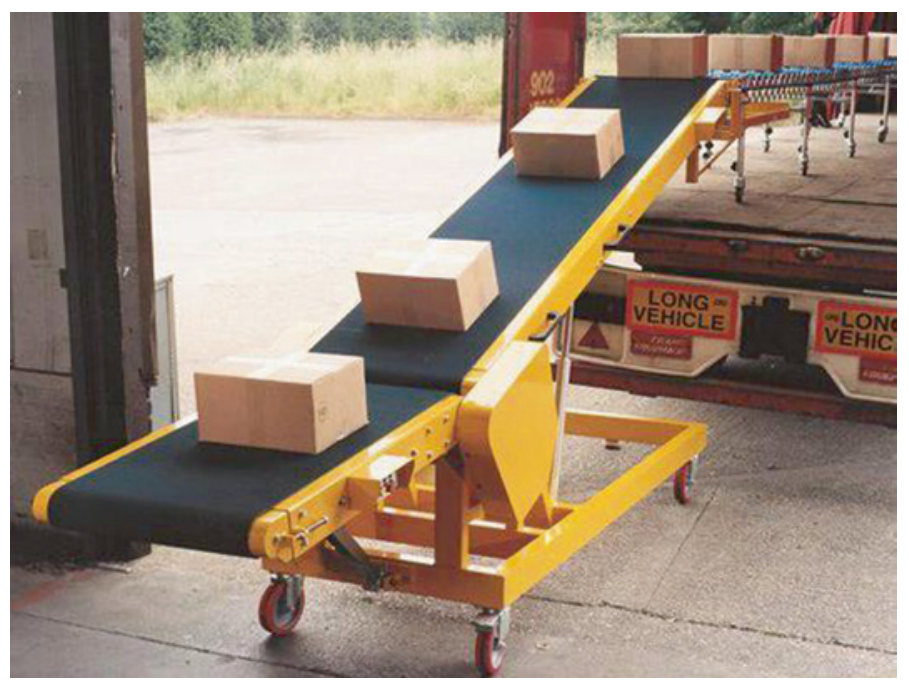

Fig. 7.4 Truck Loading/unloading conveyor systems (Reproduced with permission from University of Chiang Mai, Department of Industrial Engineering) 


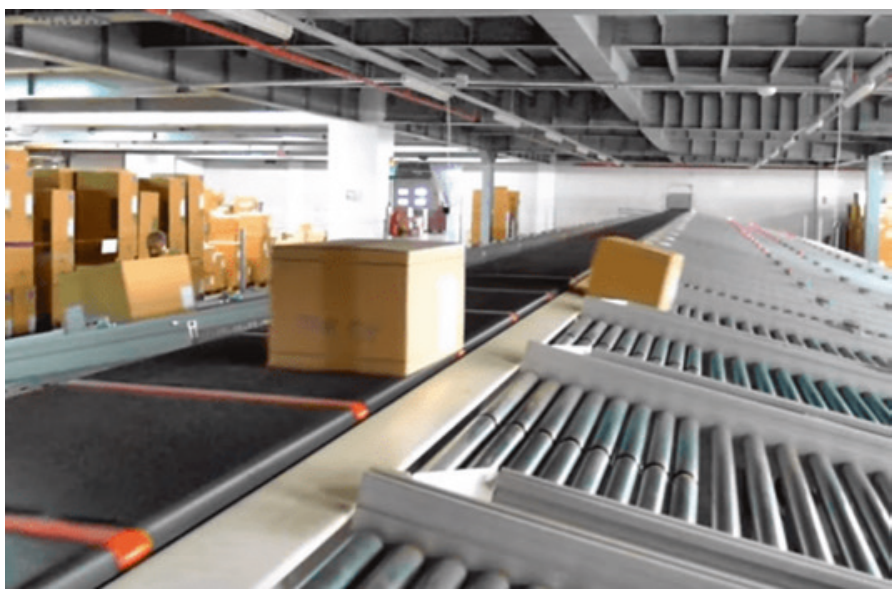

Fig. 7.5 Cross belt sorter (Reproduced with permission from University of Chiang Mai, Department of Industrial Engineering)

(b) To use closed-loop conveyor. This will help any bottleneck when picking and unloading from the belt. Often, there are many items to be picked at one destination. Then the conveyor belt must be shut to allow picker to pick all items (Fig. 7.5).

(c) To use cross belt auto sorting system and the declined roller belt. Where barcode is already embedded with the database, the item can be transferred using closed-loop conveyor. They can be autosorted. This will reduce picker load. The (b) and (c) proposals yield the Payback Period of 20-24 months. The cross-docking capacity is expected to increase by 20-30\%. Labor productivity should increase by $33 \%$. The accuracy should also increase (Fig. 7.6).

The suggestion is only preliminary. Further investigation must be made in terms of item compatibility (extra-large or out-of-shape items), equipment maintenance, facility layout, etc. The company now requests for quotation from the equipment providers for exact equipment specification and cost. 


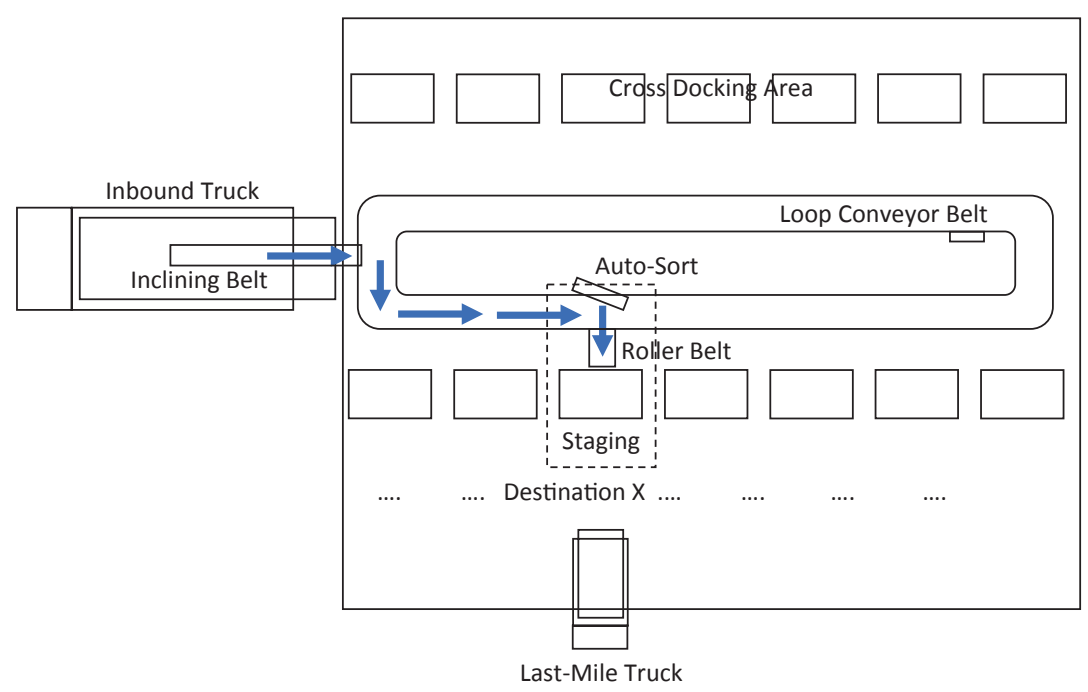

Fig. 7.6 Improved cross-docking operation

\subsection{Discussion, Suggestions, and Implications}

Logistics is among those areas strongly affected by the upcoming technologies associated with Industry 4.0 , both as an opportunity and a risk. Above all, logistics is still the imperative for providing a superior service level at feasible costs.

Automation and IT are not applied for their own sake, to be consistent with market trends, or to satisfy expectations. Automation can help to increase productivity, to lower costs, to gain flexibility, to make routine tasks more efficient, to provide workplace safety, to reduce lead times and time to market, and to improve product and service quality.

In particular, there is a huge challenge for SME to keep up with this development. They often lack the resources, and the competences, to make use of opportunities.

The authors investigated numerous literature sources on automation and information technology in logistics. The approaches and frameworks mostly focus on selected, limited aspects and research is fragmented and inhomogeneous. 
A number of basic concepts can be identified which define smart logistics within the framework of Industry 4.0. CPS, IoT, and the PI are high-level, sophisticated concepts that cannot be implemented by just buying some service or software. A step-by-step approach has to be applied, for every enterprise, much more so for SME.

Existing CNC machine tools can be connected and the majority of machines support open communication standards, such as MTConnect or OPC UA, as standards for communication and information modeling in automation. There are constraints to observe, legacy systems, technical, organizational, and financial restrictions.

Further research will be needed, with a focus on SMEs, to further investigate lower-level approaches, and technical as well as organizational solutions to satisfy the functional requirements.

\section{References}

Agus, A., and M. Shukri Hajinoor. 2012. Lean Production Supply Chain Management as Driver Towards Enhancing Product Quality and Business Performance. International Journal of Quality \& Reliability Management 29 (1): 92-121. https://doi.org/10.1108/02656711211190891.

Alpine Metal Tech GmbH. 2019. https://www.alpinemetaltech.com/ produkte_services/detail/product/60/.

Bauernhansl, T., M. ten Hompel, and B. Vogel-Heuser (eds.). 2014. Industrie 4.0 in Produktion, Automatisierung und Logistik: Anwendung, Technologien, Migration. Wiesbaden: Springer. http://dx.doi.org/10.1007/ 978-3-658-04682-8.

Birou, L., R.N. Germain, and W.J. Christensen. 2011. Applied Logistics Knowledge Impact on Financial Performance. International Journal of Operations \& Production Management 31 (8): 816-834. https://doi.org/ 10.1108/01443571111153058.

Borgmeier, A. 2017. Smart Services und Internet der Dinge: Geschäftsmodelle, Umsetzung und Best Practices: Industrie 4.0, Internet of Things (IoT), Machine-toMachine, Big Data, Augmented Reality Technologie. München: Hanser. https:// doi.org/10.3139/9783446452701.

Boyes, H., B. Hallaq, J. Cunningham, and T. Watson. 2018. The Industrial Internet of Things (IIoT): An Analysis Framework. Computers in Industry 101: 1-12. https://doi.org/10.1016/j.compind.2018.04.015. 
Broy, M. (ed.). 2010. Cyber-Physical Systems: Innovation Durch SoftwareIntensive Eingebettete Systeme. Berlin and Heidelberg: Springer. https://doi. org/10.1007/978-3-642-14901-6.

Chen, H., D.D. Mattioda, and P.J. Daugherty. 2007. Firm-Wide Integration and Firm Performance. The International Journal of Logistics Management 18 (1): 5-21. https://doi.org/10.1108/09574090710748144.

Danese, P., and M. Kalchschmidt. 2011. The Role of the Forecasting Process in Improving Forecast Accuracy and Operational Performance. International Journal of Production Economics 131 (1): 204-214. http://doi. org/10.1016/j.ijpe.2010.09.006.

Deutsche Post AG. 2015. https://www.dpdhl.com/de/presse/pressemitteilungen/2015/dhl-testet-augmented-reality-anwendung.html.

Drews, K., in: Norbert Bartneck, V. Klaas, H. Schönherr, and M. Weinländer (eds.). 2008. Prozesse optimieren mit RFID und Auto-ID: Grundlagen, Problemlösungen und Anwendungsbeispiele. Erlangen: Publicis Corporate Publishing.

Feinbier, L., Y. Yaslar, and H. Niehues. 2011. RFID-Brammenlogistik. techforum.

Finkenzeller, K. 2015. RFID-Handbuch, 7th ed. München: Carl Hanser Verlag. Glock, C., and E. Grosse (eds.). 2017. Warehousing 4.0: Technische Lösungen und Managementkonzepte für die Lagerlogistik der Zukunft (1. Aufl.). LaudaKönigshofen: B + G Wissenschaftsverlag.

Granlund, A. 2014. Facilitating Automation Development in Internal Logistics Systems. Västerås: School of Innovation, Design and Engineering, Mälardalen University. http://doi.org/10.1504/IJLSM.2014.063984.

Greenwood, N.R. 1988. Implementing Flexible Manufacturing Systems. London, UK: Macmillan Education.

Groover, M.P. 2008. Automation, Production Systems, and Computer-Integrated Manufacturing, 3rd ed. Upper Saddle River, NJ: Pearson/Prentice Hall.

Gudehus, T. 2012. Dynamische Disposition: Strategien, Algorithmen und Werkzeuge zur optimalen Auftrags-, Bestands- und Fertigungsdisposition (3. Aufl.). Berlin: Springer. http://dx.doi.org/10.1007/978-3-642-22983-1.

Henning, A., and U. Müller. 2001. Entwicklung eines maschinenlesbaren Kennzeichnungssystems für Brammen und Knüppel: Abschlußbericht. Luxembourg: Off. for Off. Publ. of the Europ. Communities.

Inboundlogistics. 2018. https://www.inboundlogistics.com/cms/article/2018-top100-logistics-it-market-research-survey/.

InfoSight Corporation. 2015. http://www.infosight.com/support/white-papers/ 68-bar-code-identification-of-hot-steel. 
Jeschke, S., C. Brecher, H. Song, and D.B. Rawat (eds.). 2017. Industrial Internet of Things. Cham: Springer.

Jost, J., T. Kirks, B. Mättig, A. Sinsel, and T.U. Trapp. 2017. Der Mensch in der Industrie - Innovative Unterstützung durch Augmented Reality: Handbuch Industrie 4.0, Bd. 1. Heidelberg: Springer.

Juga, J., J. Juntunen, and D.B. Grant. 2010. Service Quality and Its Relation to Satisfaction and Loyalty in Logistics Outsourcing Relationships. Managing Service Quality: An International Journal 20 (6): 496-510. https://doi.org/10.1108/09604521011092857.

Kiritsis, D. 2011. Closed-Loop PLM for Intelligent Products in the Era of the Internet of Things. Computer-Aided Design 43 (5): 479-501. https://doi. org/10.1016/j.cad.2010.03.002.

Krämer, K. 2002. Automatisierung in Materialfluss und Logistik: Ebenen, Informationslogistik, Identifikationssysteme, intelligente Geräte. Wiesbaden: Deutscher Universitäts-Verlag.

Lee, E.A. 2010. CPS Foundations. In Proceedings of the 47th Design Automation Conference, 737. New York, NY: ACM.

LivePerson. 2018. https://de.statista.com/statistik/daten/studie/863407/umfrage/ umfrage-zu-drohenden-jobverlusten-durch-automation-in-verschiedenen-branchen/.

Mätttig, B., T. Kirks, and J. Jost. 2016. Untersuchung des Einsatzes von Augmented Reality im Verpackungsprozess unter Berücksichtigung spezifischer Anforderungen an die Informationsdarstellung sowie die ergonomische Einbindung des Menschen in den Prozess. In Logistics Journal: Proceedings.

McGuire, P.M. 2009. Conveyors: Application, Selection, and Integration. Boca Raton, FL: CRC Press.

McKee, T., in: Colin E. Webb, and J.D.C. Jones. 2004. Handbook of Laser Technology and Applications: Applications. Bristol: Institute of Physics Publishing.

Mehami, J., M. Nawi, and R.Y. Zhong. 2018. Smart Automated Guided Vehicles for Manufacturing in the Context of Industry 4.0. Procedia Manufacturing 26: 1077-1086. https://doi.org/10.1016/j.promfg.2018.07.144.

Montreuil, B. 2011. Toward a Physical Internet: Meeting the Global Logistics Sustainability Grand Challenge. Logistics Research 3 (2-3): 71-87. https:// doi.org/10.1007/s12159-011-0045-x.

Padovano, A., F. Longo, L. Nicoletti, and G. Mirabelli. 2018. A Digital Twin Based Service Oriented Application for a 4.0 Knowledge Navigation in the Smart Factory. IFAC-PapersOnLine 51 (11): 631-636. https://doi. org/10.1016/j.ifacol.2018.08.389. 
Pan, S., E. Ballot, G.Q. Huang, and B. Montreuil. 2017. Physical Internet and Interconnected Logistics Services: Research and Applications. International Journal of Production Research 55 (9): 2603-2609. https://doi.org/10.1080/ 00207543.2017.1302620.

SCI Verkehr. 2018. https://de.statista.com/statistik/daten/studie/980502/ umfrage/megatrends-in-der-logistik-in-deutschland/.

Seegert, S. 2011. Präge- und Stempelschrifterkennung auf metallischen Oberflächen. Kölner Beiträge zur Technischen Informatik.

Spillan, J.E., M.A. McGinnis, A. Kara, and G. Liu Yi. 2013. A Comparison of the Effect of Logistic Strategy and Logistics Integration on Firm Competitiveness in the USA and China. The International Journal of Logistics Management 24 (2): 153-179. https://doi.org/10.1108/IJLM-06-2012-0045. ten Hompel, M., H. Büchter, and U. Franzke. 2008. Identifikationssysteme und Automatisierung. Berlin and Heidelberg: Springer.

ten Hompel, M., and T. Schmidt. 2005. Warehouse Management: Automation and Organisation of Warehouse and Order Picking Systems. Berlin and New York: Springer.

Tractica. 2012. https://de.statista.com/statistik/daten/studie/870614/umfrage/ prognostizierter-umsatz-mit-servicerobotern-weltweit-nach-bereichen/.

Ullmann, G., and J. Sauer. 2013. Dezentrale, agentenbasierte Selbststeuerung von Fahrerlosen Transportsystemen (FTS) (Schlussbericht, IPH - Institut für Integrierte Produktion).

Weichbold, C., E. Schuster, in: H.E. Zsifkovits, and S. Altendorfer-Kaiser (eds.). 2017. Entwicklung einer Methodik zur Verfolgung von kontinuierlichen, inhomogenen Materialflüssen und deren Eigenschaften (SmartSinter). Mering: Rainer Hampp Verlag.

Zsifkovits, H., and M. Woschank. 2019. Smart Logistics-Technologiekonzepte und Potentiale. BHM Berg- Und Hüttenmännische Monatshefte 164 (1): 42-45. https://doi.org/10.1007/s00501-018-0806-9. 
Open Access This chapter is licensed under the terms of the Creative Commons Attribution 4.0 International License (http://creativecommons. org/licenses/by/4.0/), which permits use, sharing, adaptation, distribution and reproduction in any medium or format, as long as you give appropriate credit to the original author(s) and the source, provide a link to the Creative Commons license and indicate if changes were made.

The images or other third party material in this chapter are included in the chapter's Creative Commons license, unless indicated otherwise in a credit line to the material. If material is not included in the chapter's Creative Commons license and your intended use is not permitted by statutory regulation or exceeds the permitted use, you will need to obtain permission directly from the copyright holder.

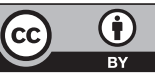

